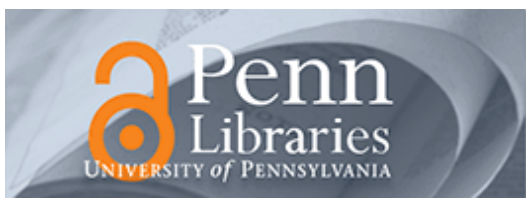

University of Pennsylvania ScholarlyCommons

Wharton Pension Research Council Working

Papers

Wharton Pension Research Council

9-1-2013

\title{
Integrated Risk Management for Defined Benefit Pensions: Models and Metrics
}

Raimond Maurer

Goethe University, maurer@finance.uni-frankfurt.de

Follow this and additional works at: https://repository.upenn.edu/prc_papers

Part of the Economics Commons

Maurer, Raimond, "Integrated Risk Management for Defined Benefit Pensions: Models and Metrics" (2013). Wharton Pension Research Council Working Papers. 116.

https://repository.upenn.edu/prc_papers/116

This paper is posted at ScholarlyCommons. https://repository.upenn.edu/prc_papers/116

For more information, please contact repository@pobox.upenn.edu. 


\title{
Integrated Risk Management for Defined Benefit Pensions: Models and Metrics
}

\begin{abstract}
The Pension Benefit Guaranty Corporation (PBGC) insures private sector defined benefit (DB) pension plans when an employer becomes insolvent and is unable to pay its pension liabilities. In principle, the insurance premiums collected by PBGC should be sufficient to cover potential losses; this would ensure that PBGC could pay the insured benefits of terminated pension plan without additional external funding (e.g. from taxpayers). Therefore, the risk exposure of the PBGC from insuring DB pension plans arises from the probability of employer insolvencies; and the terminating plans' funding status (the excess of the value of insured plan liabilities over plan assets). This paper focuses on only the second component, namely the impact of plan underfunding for the operation of the PBGC. When a DB plan is fully funded, the PBGC's risk exposure for an ongoing plan is low even if the plan sponsor becomes insolvent. Thus the questions most pertinent to the PBGC are what key risk factors can produce underfunding in a DB plan, and how can these risk factors be quantified? We explore the most important risk factors that produce DB pension underfunding, namely investment risk and liability risk. Both are interrelated and must be considered simultaneously in order to quantify the risk exposure of a DB pension plan. We propose that an integrated risk management model (an Integrated Asset/Liability Model) can help better understand DB pension plan funding risk. We also examine the Pension Insurance Modeling System developed by the PBGC in terms of its own use of some of the building blocks of an integrated risk management model.
\end{abstract}

\section{Disciplines}

Economics 


\title{
Integrated Risk Management for Defined Benefit Pensions: Models and Metrics
}

\author{
Raimond Maurer
}

September 2013

\author{
PRC WP2013-10 \\ Pension Research Council Working Paper \\ Pension Research Council \\ The Wharton School, University of Pennsylvania \\ 3620 Locust Walk, 3000 SH-DH \\ Philadelphia, PA 19104-6302 \\ Tel.: 215.898.7620 Fax: 215.573.3418 \\ Email:prc@wharton.upenn.edu \\ http://www.pensionresearchcouncil.org
}

The research reported herein was pursuant to a grant from the U.S. Social Security Administration (SSA) funded as part of the Retirement Research Consortium (RRC); the author also acknowledges support from The Pension Research Council at The Wharton School. All findings and conclusions expressed are solely those of the author and do not represent the views of the SSA or any agency of the federal government, the MRRC, the PRC, or The Wharton School at the University of Pennsylvania. All findings, interpretations, and conclusions of this paper represent the views of the authors and not those of the Wharton School or the Pension Research Council. (C)2013 Pension Research Council of the Wharton School of the University of Pennsylvania. All rights reserved. 


\title{
Integrated Risk Management for Defined Benefit Pensions: Models and Metrics
}

\begin{abstract}
$\underline{\text { Abstract }}$
The Pension Benefit Guaranty Corporation (PBGC) insures private sector defined benefit (DB) pension plans when an employer becomes insolvent and is unable to pay its pension liabilities. In principle, the insurance premiums collected by PBGC should be sufficient to cover potential losses; this would ensure that PBGC could pay the insured benefits of terminated pension plan without additional external funding (e.g. from taxpayers). Therefore, the risk exposure of the PBGC from insuring DB pension plans arises from the probability of employer insolvencies; and the terminating plans' funding status (the excess of the value of insured plan liabilities over plan assets). This paper focuses on only the second component, namely the impact of plan underfunding for the operation of the PBGC. When a DB plan is fully funded, the PBGC's risk exposure for an ongoing plan is low even if the plan sponsor becomes insolvent. Thus the questions most pertinent to the PBGC are what key risk factors can produce underfunding in a DB plan, and how can these risk factors be quantified? We explore the most important risk factors that produce DB pension underfunding, namely investment risk and liability risk. Both are interrelated and must be considered simultaneously in order to quantify the risk exposure of a DB pension plan. We propose that an integrated risk management model (an Integrated Asset/Liability Model) can help better understand DB pension plan funding risk. We also examine the Pension Insurance Modeling System developed by the PBGC in terms of its own use of some of the building blocks of an integrated risk management model.
\end{abstract}

\author{
Raimond Maurer \\ Chair of Investment, Portfolio Management and Pension Finance \\ Goethe University Frankfurt \\ Metzler Visiting Professor \\ The Wharton School, University of Pennsylvania \\ House of Finance \\ Gruneburgplatz 1 \\ 60323 Frankfurt am Main \\ Germany \\ maurer@finance.uni-frankfurt.de
}




\title{
Integrated Risk Management for Defined Benefit Pensions: Models and Metrics
}

\author{
Raimond Maurer
}

\section{Introduction}

The Pension Benefit Guaranty Corporation (PBGC) is an agency of the U.S. federal government that insures private sector defined benefit pension (DB) plans when an employer becomes insolvent and is unable to pay its pension liabilities. When a plan is terminated, the PBGC takes over the plan assets and pays vested employees their future benefits up to certain limits (trusteed plans). For this insurance coverage, employers of ongoing plans (non-trusteed) must pay fixed/variable premiums to the PBGC. In principle, the insurance premiums collected by PBGC should be sufficient to cover potential losses; this would ensure that PBGC could pay the insured benefits of terminated pension plan without additional external funding (e.g. from taxpayers). Therefore, the risk exposure of the PBGC from insuring DB pension plans arises from two sources:

(1) the probability of employer insolvencies; and

(2) the terminating plans' funding status (the excess of the value of insured plan liabilities over plan assets).

This paper focuses on only the second component, namely the impact of plan underfunding for the operation of the PBGC. When a DB plan is fully funded (i.e. the value of plan assets is equal to the value of the plan liability), the PBGC's risk exposure for an ongoing plan is low even if the plan sponsor becomes insolvent. For this reason, the questions most pertinent to the PBGC are: what key risk factors can produce underfunding in a DB pension plan, and how can these risk factors be quantified? 
In what follows, we explore the most important risk factors that produce DB pension underfunding, namely investment risk and liability risk. Both are interrelated and must be considered simultaneously in order to quantify the risk exposure of a DB pension plan (Hustead and Mitchell 2001). Therefore researchers and practitioners have argued that there is a need for an integrated risk management model—also referred as Integrated Asset/Liability Model—to better understand DB pension plan funding risk. We also examine the Pension Insurance Modeling System (PIMS) developed by the PBGC in terms of its own use of some of the building blocks of an integrated risk management model.

The PIMS uses detailed information on liabilities of terminated and ongoing plans. It also implements a wide range of detailed legal rules, i.e. contribution requirements from the Pension Protection Act (PPA), rules from the U.S. tax code, and the way that fixed/variable PBGCpremiums are calculated. It also includes simple management rules on how the assets of the terminated and ongoing plans are invested. ${ }^{1}$ Based on seven key stochastic variables, ${ }^{2}$ PIMS

${ }^{1}$ PBGC assets are invested in a revolving and a trust fund. Plan specific asset returns (stocks and bonds) of ongoing plans are modeled using a set of factor-equations (see equation 5-10; PIMS Description, page 5-7) calibrated using historical Form 5500 information. It should be mentioned that PIMS do not include a time varying asset allocation depending on the funding status of the specific plan. Therefore moral hazard aspects, i.e. a possible increase of the equity exposure in the case of a (very) low funding status are not modeled.

${ }^{2}$ See Table 2-14 and calibrated equation 5-4 to 5-10 in PIMS Description (2010): Nominal interest rate, real stock return, equity-to-debt ratio, employment, cash-flow-to assets, firm equity, plan asset returns. Important deterministic user inputs are the real interest rate and productivity growth. 
specifies for each simulation path $\mathrm{i}=1, \ldots . \mathrm{I}$ and time period $\mathrm{t}=1, \ldots ., \mathrm{T}$ for each ongoing plan $\mathrm{m}=1, \ldots, \mathrm{M}$ and $\mathrm{n}=1, \ldots, \mathrm{N}$ terminated plan $^{3}$ :

1) the funding status (value of plan assets minus actuarial value of plan liabilities)

2) the cash flows from assets, the premiums paid to PBGC from ongoing plans, and the benefits paid to retirees of terminated plans

3) the probability of insolvency for ongoing plans.

By doing so, PIMS considers both pure and parameter risk in the simulation procedure. The resulting simulations produce a wide range of potential future outcomes of claims. These outcomes are reported in various summary statistics, e.g. as distributions over time (using quantiles, averages) and/or as a stochastic present value of PBGC net financial position using the riskless interest rate to discount (on each path) future payments.

Overall, we conclude that the PBGC has developed a complex, reasonably sensible, and defensible stochastic model to predict the probability distribution of potential future losses for PBGC from both terminated and ongoing DB-plans. Additionally we outline two key areas where extensions of PIMS may be valuable in the future:

- Incorporate systematic mortality risk in the liability part of the model

- Model the complete term structure of interest rate instead of only a single interest rate (30-year government bonds).

Besides these two areas, the model should be expanded to include not only equity and bonds, but also real estate and alternative investments. And finally, the Conditional Value-at-Risk metric may be a useful way to communicate the model outcomes.

\footnotetext{
${ }^{3}$ Typical values are $\mathrm{I}=500$ runs, $\mathrm{T}=20$ years.
} 


\section{Liability Risk}

General aspects. DB plan liabilities evolve as a function of various demographic assumptions, economic assumptions, and assumptions about future benefit flows. The actuarial profession has established well-developed standards on how to set and work with such assumptions when evaluating the current liabilities of a pension plan. Yet the future realizations of these factors may differ from expectations, and/or the assumption may change which results in fluctuations in the value of the plan liabilities (liability risk). For example, actuaries use a specific mortality table to specify the present value of future benefits. But realized mortality rates for a specific pension plan could be higher or lower than those of the assumed mortality table. Such uncertainty is referred as idiosyncratic mortality risk. In addition, mortality can also change systematically because of unexpected improvements in survival probabilities (systematic mortality risk). Research shows that especially for long term liabilities like pension benefits, systematic mortality risk is an important and often underestimated risk factor. ${ }^{4}$

Figure 1 illustrates the impact of systematic mortality risk, ${ }^{5}$ indicating that the probability of living to advanced ages exhibits significant dispersion. For example, the probability of attaining age 70 spans the range from $79-93 \%$, with a median of $87 \%$. Thus the range of the expected lifetime remaining from age 20 varies between 56.7 and 73.8 years, with a median of 64.5 years. Thus a stochastic mortality model shows that future survival rates and years of life remaining are likely to substantially exceed those derived from the deterministic scenario.

Figure 1 here

\footnotetext{
${ }^{4}$ See Cairns et al. (2010).

${ }^{5}$ This section builds on Maurer et al. (2013).
} 
To indicate the economic cost of stochastic mortality, one can calculate the agedependent implied loadings for pre-selected confidence levels that an insurance company or a pension fund must charge for providing lifelong annuity benefits (deferred until age 67). For each initial age, these are derived by sampling 10,000,000 realizations of the stochastic mortality process.

Figure 2 here

Figure 2 shows that premium increases which take into account stochastic mortality can be substantial, especially for younger annuitants. For example, providers must charge 20-yearold buyers loadings of around 32\% on top of the actuarially fair premium, to maintain a 99.99\% solvency confidence level. At the $99.5 \%$ confidence level, loadings must amount to over $20 \%$ for this age group. At later ages, the dispersion of possible future mortality outcomes decreases and so does the implied loading. Nevertheless, at age 66, loadings required to meet the $99.99 \%$ (99.5\%) confidence level still amount to around 14\% (9\%).

Assumptions in the PIMS model. Overall, the liability section of PIMS relies on professional actuarial standards for evaluating the current liabilities of the DB pension plans they insure. In addition, the PIMS model provides a methodology to project the uncertainty of future liabilities by varying population dynamics (firm employment), interest rates and benefit growth. ${ }^{6}$ To discount future liabilities, PIMS uses the yield for corporate bonds. The corporate bond yield is a function of the (simulated) nominal interest rate for government bond plus a spread and an adjustment factor. Due to their long-term character, pension liabilities have a long duration and

$6 \quad$ Note: the stochastic evolution of benefit growth depends (indirectly) on the evolution of interest rates. 
therefore are sensitive to the discount rate selected. There is an ongoing debate as to whether a (higher) discount rate other than the yield for (quasi) risk-free government bonds is appropriate ${ }^{7}$.

Yet systematic mortality risk is currently not incorporated in the PIMS model. A large literature has developed over the last two decades exploring the stochastic development of historical human mortality patterns. ${ }^{8}$ In their foundational work, Lee and Carter (1992) introduced a simple discrete-time one-factor model for the central death rate and employed it to describe the evolution of U.S. mortality rates. While this model was able to trace the (downward sloping) time trend in mortality, the one-factor approach implied perfect correlation of mortality innovations over all ages, an implication contradicted by empirical evidence. Subsequent stochastic mortality models seek to remedy this by taking a multi-factor approach (e.g. Cairns et

7 This debate is also referred as the difference between an actuarial versus an economic valuation of pension liabilities. Traditionally, actuaries choose the discount rate which reflects a reasonable projected expected return of the asset backing the pension liabilities. If the pension assets are partly invested in equities, the discount rate includes also an equity risk premium, which is from an ex ante perspective not realized. By contrast, many economists argue that the relevant number for discounting future pension payments is the riskless rate of interest rate reflecting the financing cost of the plan sponsor to build up a replicating portfolio. See Blake (2006:77).

8 For a detailed discussion of alternative approaches see Pitacco et al. (2009), Cairns et al. (2006a), as well as Cairns et al. (2010). 
al. 2006b; Renshaw and Haberman 2003). Currently, the parsimonious two-factor model ${ }^{9}$ by Cairns, Blake, and Dowd is widely used as a model for stochastic mortality.

\section{Investment Risk}

General aspects. The pension plan assets are invested in various categories, e.g. stocks, fixed income instruments, real estate, and alternative investments. The future returns of these assets typically fluctuate over time and could be lower than the assumed interest rate used to discount future benefits (investment risk). Fluctuating interest rates (a spot rate curve) are particularly important, because they simultaneously affect the development of the plan assets and the evaluation of plan liabilities. Therefore it is necessary to model the long run stochastic dynamics of interest rates and future returns on the various assets accumulated in the pension plan. Various models are documented in the literature, ${ }^{10}$ which also notes that the modeling of illiquid assets (e.g. real estate or alternative assets) represents a big challenge. ${ }^{11}$

9 Renshaw and Haberman (2003) examine the forecasting performance of various stochastic mortality models and show that the CBD model provides a good fit, especially for age 50 onwards; it is somewhat less accurate for younger ages. Nevertheless, since we calibrate and model mortality dynamics over the complete life-cycle (age 20-120) within a dynamic portfolio choice model, the CBD two factor-model is a good compromise between the empirical evidence, parsimonious structure, and computational burden (in terms of state variables).

${ }^{10}$ Many popular model use a first order vector autoregressive process (VAR 1); see Campbell et al. (2003) and Hoevenaars et al. (2008). More recent developments use a Markov-Regime Switching approach (see Guidolin and Timmermann 2007). While these models capture the short term (e.g. daily, weekly, monthly) probability distribution of risky assets reasonable (i.e. 
Specific comments on the PIMS model. Currently PIMS uses a VAR approach to model two asset classes, risky stocks and bonds. The returns for bonds (interest and capital gains) depend on the development of the nominal interest rate and a duration adjustment for capital gains. Stock returns are modeled independent identically distributed. The return on corporate bonds is assumed to depend on the interest rate level adjusted for a possible (but certain) spread. The model parameters are calibrated using U.S. data. Additional assets like real estate or alternative assets are not included in the model. The range of asset holdings for specific pension plans is approximated using historical Form 5500 information. PIMS also allows plans to smooth asset values within the context of the minimum PPA funding rules. Plan assets of PPGC are invested first in long term bonds (and T-bills) to immunize the liabilities. For the trust fund equity investments are allowed within limits.

Overall, the PIMS investment model is a reasonable approach, providing a good compromise between the tractability of the model (length, time of running the code and calibration of model parameters) and the need to use plan specific information. Useful extensions would include additional asset classes (e.g. real estate), the modeling of uncertainty of the spread for corporate bonds, and (most important) a complete term structure model for nominal interest rates.

skewness, excess-kurtosis), for long term returns it is not clear if the substantially higher complexity to calibrate such models is justified.

${ }^{11}$ See Appendix A for one way to model real estate investments. 


\section{Integrating Assets and Liabilities: The Key Importance of the Interest Rate}

Besides the budget equations and the correlations of (the residuals of) the stochastic variables, the nominal interest rate is of key importance for PIMS. The nominal interest rate enters in the following components in the PIMS model in several ways:

1. Actuarial Valuation of Liabilities of terminated/ongoing plans ${ }^{12}$

2. Minimum Contribution Rules according to PPA rules

3. Specifying the return on plan assets for ongoing plans (stock and bonds)

4. Specifying the return PBGC assets for terminated plans (stock and bonds)

5. Yield for corporate bonds $=(i+$ spread $) * a d j$. factor

6. Inflation rate $=(1+i) /(1+$ fix real interest rate $)-1$.

7. Nominal benefit (wage) growths (since inflation is related to the nominal interest rate)

8. Calculation of the stochastic present value of PBGC claims

In the current version of PIMS, the nominal interest is modeled and calibrated as a single stochastic variable for U.S. government bonds with a maturity of 30 years. Such an approach does not allow for any variation in the shape (curvature) of the term structure, nor does it include any uncertainty in credit spreads. This is not state of the art in Asset-Liability-Modeling, nor is it consistent with empirical fluctuations of the term structure. For example, the current term structure is very steep ( $0 \%$ for T-bills and 3\% for 30 maturities). Given the key importance of the

12 “The interest assumption for the annul valuation of ongoing plans is currently based on the 24 months average of the corporate bond rates; captured via a single effective interest rate. Alternatively, the three segment rates can be used for PIMS valuation. During the simulation, the underlying bond rates are assumed to change by a stochastic adjustment process” (PIMS System Desc. 3-13)” 
interest rate for PIMS using only one single random variable may be too parsimonious. One way to extend PIMS would model the complete term structure of interest rates. Such a term structure can be used to discount future benefits ${ }^{13}$ and also to model the development of fixed income assets in terminated and ongoing plans. Various (arbitrage free) term structure models (including procedure to calibrate the parameters) are available ${ }^{14}$.

\section{Communication of Outcomes: Conditional Value-at-Risk}

One outcome from the PIMS model is the distribution of the stochastic present values of the agency's future net positions using a 10-year horizon (except for the 20 year probability of PBGC insolvency). One way to communicate this distribution by a risk measure is to use the Conditional Value-at-Risk of pension cost at a certain confidence level $x$ (e.g. 95\%). The x\%Conditional Value-at-Risk ( $\mathrm{CVaR})$ is defined as the expected present value of total future net liabilities under the condition that its realization is greater than the Value-at-Risk (VaR) for that level. The CVaR framework as a measure of risk is in many ways superior to the commonlyused Value-at-Risk measure, i.e. the costs that will not be exceeded with a given probability. In particular, the CVaR focuses attention on a given percentile of a loss distribution, and it also accounts for the magnitude of losses in the distributional tails beyond this percentile ${ }^{15}$. The

13 In the sense of a replication bond portfolio to match future liabilities.

14 See Balduzzi et al. (1996) or the book by Cairns (2004). The Federal Reserve Bank uses a 3-factor model for the U.S. term structure:

http://www.newyorkfed.org/research/staff_reports/research_papers/9619.html.

15 For a detailed discussion of the advantages of the CVaR over the more widely acknowledged VaR see, e.g., Artzner et al. (1999). 
CVaR risk metric could be a promising way to communicate risk to policymakers. In addition, this risk measure is consistent with important theoretical properties (e.g. it is a coherent risk measure).

Figure 3 illustrates the $\mathrm{CVaR}$ of the (stochastic) present value of costs for different investment strategies that might be used to fund the benefits of a defined benefit pension plan. ${ }^{16}$ The range of the optimal portfolio is substantially smaller than for pure equity or bond investments, while investing only in real estate would result in an even smaller range. The overall level of costs resulting from following the optimal strategy is also substantially lower, compared to the pure real estate investment case. Figure 3 illustrates the benefit of diversification to minimize the worst-case risk of pension costs represented with the CVaR.

Figure 3 here

\section{Conclusions}

Overall, the PIMS model is an important tool for modeling the liability risk of pension plans insured by PBGC. There is, to my knowledge, no other documented model available that can do a comparable job. Nevertheless, there are several opportunities for extensions:

- Incorporating systematic mortality risk

16 The results are based on an ALM-study of a large (German) public DB pension plan; see Maurer et al. 2009. Here, pension costs are defined as the stochastic present value of regular and supplementary (additional required in an underfunding situation) into the pension plan by the plan sponsors using a 50 year horizon). An illustration of a general ALM model appears in Appendix B. 
- Incorporation of a stochastic investment model for the major asset classes beyond stocks and bonds (including real estate).

- $\quad$ The modeling of the full term structure of interest rate. 


\section{Appendices}

Appendix Figure A1 here

\section{Appendix A: Modeling Real Estate}

Deriving reliable return time series for real estate as an asset class is difficult due to the peculiarities of property investments ${ }^{17}$. In contrast to equity and bond indices, inhomogeneity, illiquidity, and infrequent trading in individual properties result in transaction-based real estate indices not being able to adequately describe the returns generated in these markets. Moreover, such price indices do not account for rental income, which constitutes a significant source of return on real estate investments. By contrast, it is comparably easy to construct indices that try to approximate the income on direct real estate investments by using the return on investing indirectly through traded property companies like real estate investment trusts (REITs). However, empirical evidence on these forms of indirect real estate investments suggests that they exhibit a more equity-like behavior ${ }^{18}$. These indices are therefore a much less than perfect proxy for direct real estate investments (see Hoesli and MacGregor 2000).

Appraisal-based indices are widely used representatives for real estate investments. These indices account for easy to sample continuous rental income as well as for returns from changes in property values, which are estimated through periodic appraisals by real estate experts. As individual properties' values are usually estimated only once a year and due to the fact that there

17 This section is based on Maurer et al. (2009). For discussion of design and characteristics of real estate indices we refer to Hoesli and MacGregor (2000, Ch. 4).

18 In a survey by Eichholtz (1997), correlations between common equities and property company shares range from 0.12 to 0.96 . 
is no single valuation date for all properties, not every return observation in the index can be substantiated with a new and observation date consistent appraisal of the overall property portfolio underlying the index. Moreover, annual appraisals often draw significantly on prior valuations. Consequently, returns derived from appraisal-based indices exhibit substantial serial correlation and low short term volatilities that understate the true volatility of real estate returns. Different methodologies have been suggested to reduce undue smoothing in real estate return time series, which subsequently will exhibit more realistic levels of volatility ${ }^{19}$. To overcome this problem, the approach developed by Blundell and Ward (1987) suggests transforming the original (smoothed) return series according to:

$$
r_{t}^{*}=\frac{r_{t}}{1-a}-\frac{a}{1-a} r_{t-1}
$$

where $r^{*}$ represents the unsmoothed return in $t$ and $a$ the coefficient of first-order autocorrelation in the return time series. Under this transformation, expected returns remain constant, $\mathrm{E}\left(r^{*}\right)=$ $\mathrm{E}\left(r_{t}\right)$, but the return standard deviation increases according to:

$$
\operatorname{STD}\left(r_{t}^{*}\right)=\operatorname{STD}\left(r_{t}\right) \sqrt{\frac{1-a^{2}}{(1-a)^{2}}}
$$

19 Other methods to unsmooth real estate return time series have been suggested by among others - Firstenberg et al. (1988), Ross and Zisler (1991), Fisher et al. (1994). 


\section{References}

Artzner, P., F. Delbaen, J. Eber, and D. Heath (1999). “Coherent Measures of Risk,” Mathematical Finance, 9: 203 - 228.

Barkham, R., and D. M. Geltner (1994). "Unsmoothing British Valuation-based Returns without Assuming an Efficient Market," Journal of Property Research, 11: 81-95.

Balduzzi, P., S. Ranjan Das, S. Foresi, and R. Sundraram (1996). “A Simple Approach to Threefactor Affine Term Structure Models,” Journal of Fixed Income, December: 43-52.

Blake, D. (2006). Pension Finance. West Sussex.

Blundell, G. F., and C. W. Ward (1987). "Property Portfolio Allocation: A Multi-factor Model," Land Development Studies, 4: 145-156.

Cairns, A. (2004). Interest Rate Models: An Introduction. Princeton, NJ: Princeton University Press.

Cairns, A., D. Blake, and K. Dowd (2006a). "Pricing Death: Frameworks for the Valuation and Securitization of Mortality Risk,” ASTIN Bulletin, 36: 79-120.

Cairns, A., D. Blake, and K. Dowd (2006b). "A Two-factor Model for Stochastic Mortality with Parameter Uncertainty: Theory and Calibration,” Journal of Risk and Insurance, 73: 687718.

Cairns, A., D. Blake, K. Dowd, G. Coughlan, D. Epstein, and M. Khalaf-Allah (2010). “A Framework for Forecasting Mortality Rates with an Application to Six Stochastic Mortality Models,” Pensions Institute Discussion Paper PI-0801. London, U.K.: The Pensions Institute. 
Campbell, J. Y.; Y. L. Chan, and L. M. Viceira (2003). “A Multivariate Model of Strategic Asset Allocation,” Journal of Financial Economics, 67: 41-80.

Eichholtz, P. M. (1997). “Real Estate Securities and Common Stocks: A First International Look,” Real Estate Finance, 14: 70-74.

Firstenberg, P. M., S. A. Ross, and R. C. Zisler (1988). “Real Estate: The Whole Story,” Journal of Portfolio Management, 14: 22-34.

Fisher, J. D., D. M. Geltner, and R. B. Webb (1994). "Value Indices of Commercial Real Estate: A Comparison of Index Construction Methods,” Journal of Real Estate Finance and Economics, 9: 137-164.

Guidolin, M. and A. Timmermann (2007). “Asset Allocation Under Multivariate Regime Switching,” Journal of Economic Dynamics and Control, 31(11): 3503-3544.

Hoesli, M., and B. D. MacGregor (2000). Property Investment: Principles and Practice of Portfolio Management. Harlow: Pearson.

Hoevenaars, R. P., R. D. Molenaar, P. C. Schotman, and T. B. Steenkamp (2008). "Strategic Asset Allocation with Liabilities: Beyond Stocks and Bonds,” Journal of Economic Dynamics and Control, 32: 2938-2970.

Hustead, E. C., and O. S. Mitchell (2001). "Public Sector Pension Plans,” in O. S. Mitchell and E. C. Hustead, eds., Pensions in the Public Sector. Philadelphia: University of Pennsylvania Press, pp. 3-10.

Lee, R., and L. Carter (1992). "Modeling and Forecasting U.S. Mortality,” Journal of the American Statistical Association, 87: 659-671.

Maurer, R., O. S. Mitchell, and R. Rogalla (2009): "Reforming German Civil Servant Pensions: Funding Policy, Investment Strategy, and Intertemporal Risk Budgeting,” in O. S. 
Mitchell and G. W. Anderson, eds., The Future of Public Employee Retirement Systems. Oxford: Oxford University Press, pp. 32-50.

Maurer, R., O. S. Mitchell, R. Rogalla, and V. Kartashov (2013). “Lifecycle Portfolio Choice with Systematic Longevity Risk and Variable Investment-Linked Deferred Annuities,” The Journal of Risk and Insurance, forthcoming.

Pension Benefit Guaranty Corporation (PBGC) (2010). PIMS System Description, Version 1.0. Washington, DC: PBGC.

Pitacco, E., M. Denuit, S. Haberman, and A. Olivieri (2009). Modeling Longevity Dynamics for Pensions and Annuity Business. Oxford: Oxford University Press.

Renshaw, A., and S. Haberman (2003). "Lee-Carter Mortality Forecasting with Age-specific Enhancement,” Insurance: Mathematics and Economics, 33: 255-272.

Ross, S. A. and R. C. Zisler (1991). "Risk and Return in Real Estate,” The Journal of Real Estate Finance and Economics, 4(2): 175-190. 


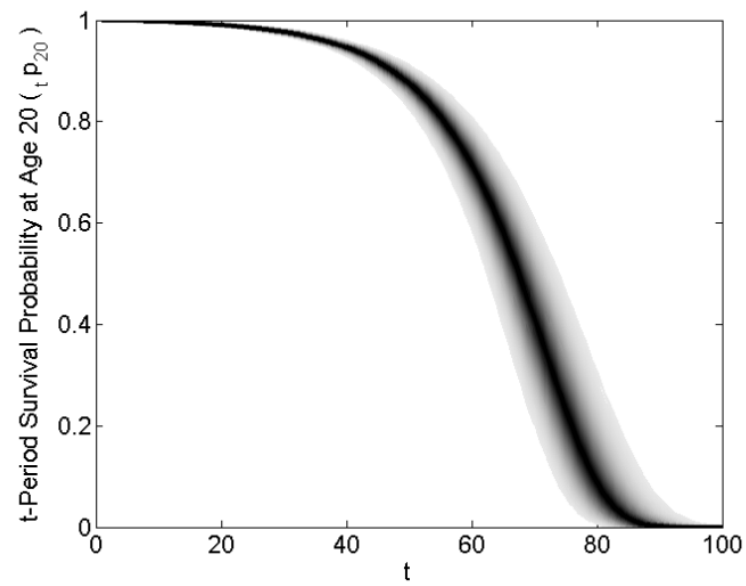

Figure 1. Systematic mortality risk: Distribution of survival probability: Age 20 female. Notes: Simulated distribution of age-20 female t-period survival probabilities (99\%:1\%) based on Cairns, Blake, and Dowd (2006b) mortality model (for parameters see text; $\mathrm{N}=10,000$ simulations). Darker areas represent higher probability mass. Source: Maurer et al. (2013). 


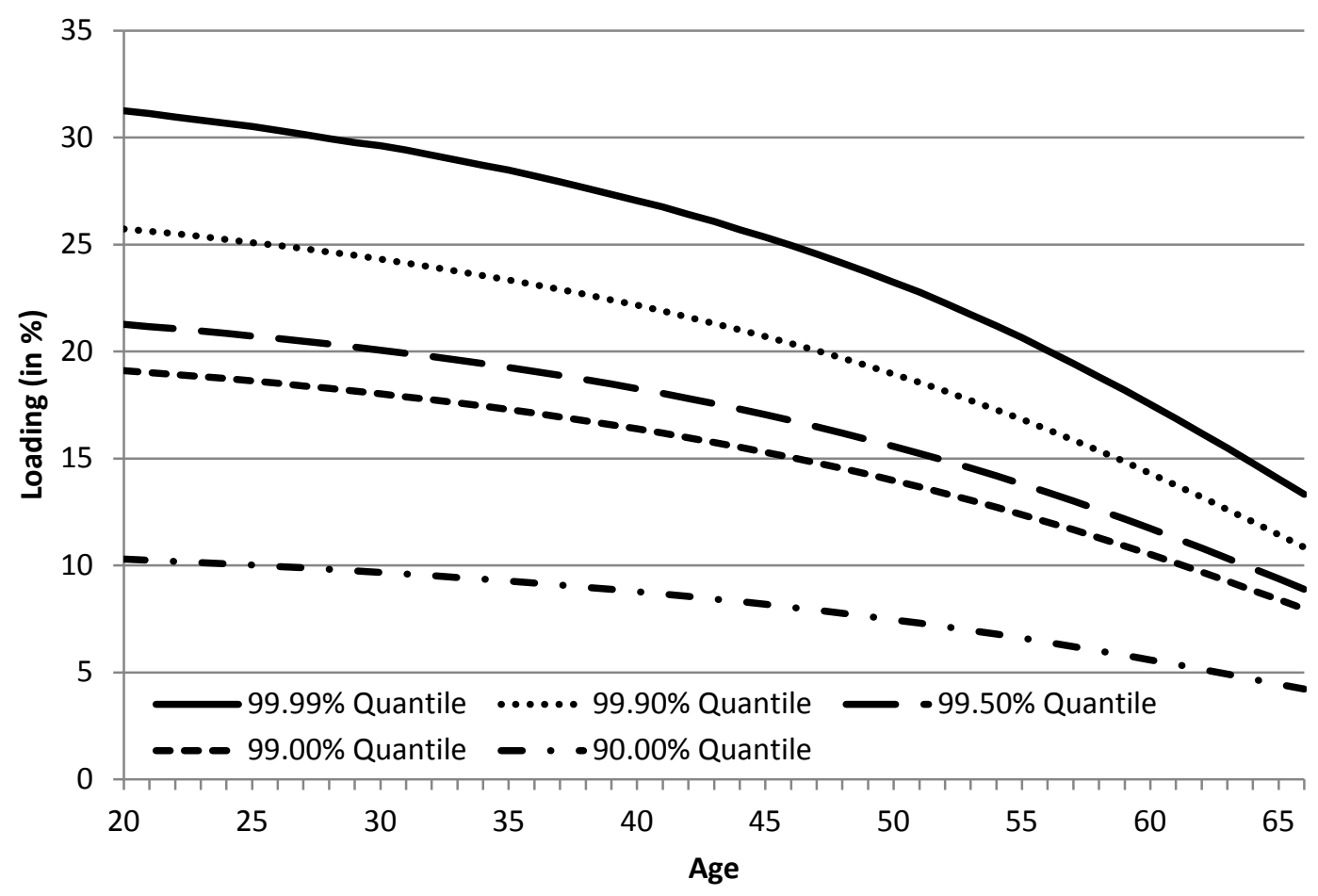

Figure 2. Stochastic mortality and risk charges for annuity benefits. Notes: The implied loadings represent additional premiums relative to the average number of required Fund Units (FUs) that must be charged to U.S. females for purchases at various ages to provide the VILDA at the specified confidence level. VILDA payments commence at age 67 with one initial FU and decrease thereafter according to the AIR (3\%). Confidence levels are based on the distribution of required FUs calculated for each of 10,000,000 simulated mortality paths using the Cairns, Blake, and Dowd (2006b) two-factor stochastic mortality model fitted to U.S. mortality tables from 1933-2007 (the assumed maximum age is 120). Source: Maurer et al. (2013). 


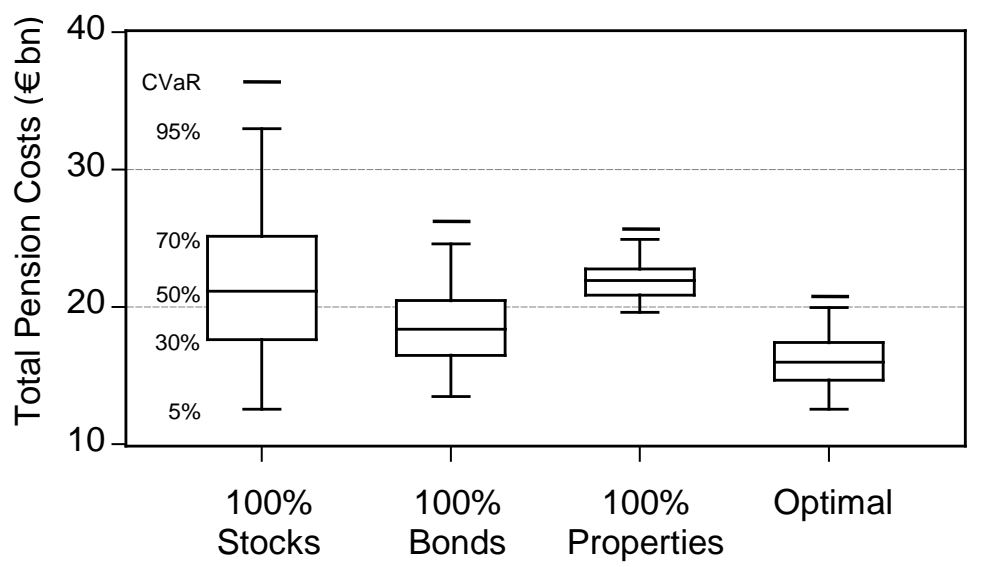

Figure 3. Illustration of $\mathrm{CVaR}$ to communicate the range of pension costs. Notes: Total Pension Costs defined as net of Regular and Supplementary Contributions using 3\% discount rate. Annotations refer to the respective percentiles of total pension cost distributions for various asset allocations. Source: Maurer, Mitchell, and Rogalla (2009). 


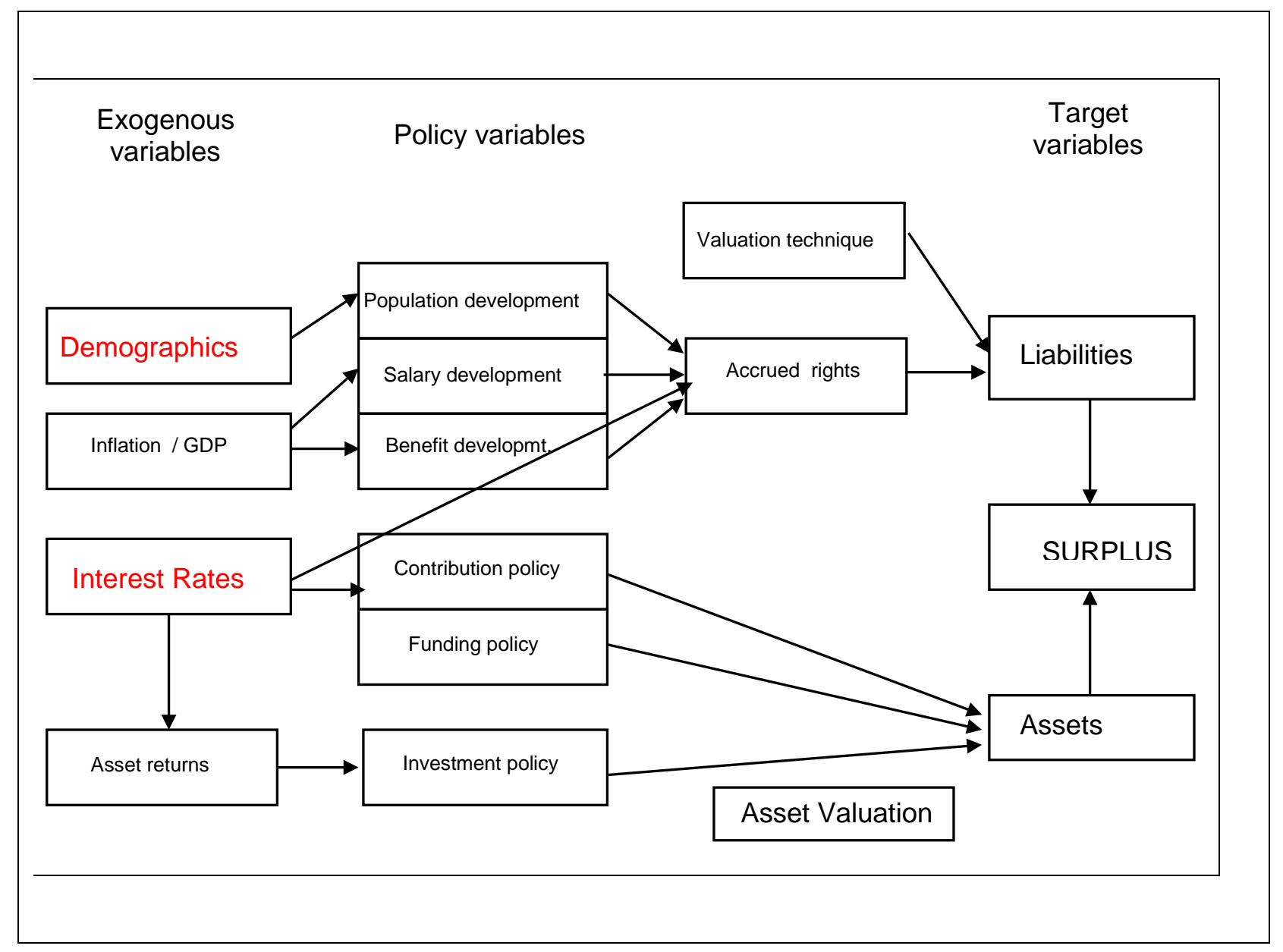

Figure A1. General structure of integrated ALM models. Source: Author's elaboration. 